\title{
Androgen modulation of pro-inflammatory and anti- inflammatory cytokines during preadipocyte differentiation
}

\author{
Silvia Pierotti, Francesca Lolli, Rosa Lauretta, \\ Chiara Graziadio, Carla Di Dato, Emilia Sbardella, \\ Maria Grazia Tarsitano, Aldo Isidori, Vincenzo \\ Bonifacio, Andrea Lenzi and Andrea M. Isidori*
}

Department of Experimental Medicine, Sapienza University of Rome, Rome, Italy

\begin{abstract}
Background: Macrophages and adipocytes contribute to release of cytokines resulting in the chronic inflammatory profile of the metabolic syndrome. The local increase of proinflammatory cytokines impairs adipogenesis, resulting in formation of dysfunctional adipocytes that are unable to store and handle lipids. The altered lipid fluxes in/from adipocytes affect whole-body metabolism. We investigated the role of androgens on adipocyte-derived proinflammatory and antiinflammatory cytokines during preadipocyte differentiation. Materials and methods: Various differentiation methods were used to obtain full conversion of 3T3-L1 into mature adipocytes. The degree of adipocyte conversion in the presence/absence of dihydrotestosterone (DHT) was analyzed by measuring intracellular triglycerides (Oil Red $\mathrm{O}$ staining). The effects of DHT administration on interleukin $1 \beta$ (IL$1 \beta)$, IL-2, IL-6, IL-10, IL-12, interferon $\gamma($ IFN $\gamma$ ) and tumor necrosis factor $\alpha(\mathrm{TNF} \alpha)$ secretion was measured at days 0 , 4,6 and 8 of differentiation using the SearchLight multiplex protein array.

Results: DHT regulates a number of cytokines in committed and mature 3T3-L1 adipocytes. IL-1 $\beta$ and TNF $\alpha$ were readily suppressed at the very early stages of differentiation. IFN $\gamma$ release was inhibited at day 4 , but the effect was no longer detectable on day 8 . IL-6 and IL-12 were significantly reduced at day 8 of differentiation. Conversely, the differentiation-dependent increase of IL-2 and IL-10 was further stimulated by DHT since day 0 .

Conclusions: We provide evidence that androgens promote an anti-inflammatory profile that parallels the acquisition of a functional adipocyte phenotype. The crosstalk between androgens, adipocyte-derived mediators of inflammation and intracellular lipid fluxes could have profound implications on metabolism of men with obesity and metabolic syndrome.
\end{abstract}

Keywords: adipogenesis; adipokines; metabolic syndrome; obesity; testosterone.

*Corresponding author: Andrea M. Isidori, MD, PhD, Department of Experimental Medicine, Sapienza University of Rome, Viale del Policlinico 155, 00161 Rome, Italy

Phone: +39-0649970540, Fax: +39-064455345,

E-mail: andrea.isidori@uniroma1.it

Received October 14, 2010; accepted October 15, 2010;

previously published online January 21, 2011

\section{Introduction}

The chronic, low-grade, inflammatory state characterizing metabolic diseases, such as obesity and endothelial dysfunction, is sustained by adipokines and by proinflammatory mediators released, locally, by white adipose tissue. The differential contribution of committed preadipocytes and mature adipocytes to the pool of secreted adipokines has recently been investigated (1). In normal conditions, immature preadipocytes contributes more, than mature adipocytes, to the proinflammatory state, because these cells exhibit a higher expression of plasminogen activator inhibitor-1 (PAI-1), interleukin 6 (IL-6), vascular endothelial growth factor, monocyte chemoattractant protein-1 (MCP-1), IL-4 and IL-8. Conversely, adiponectin, a marker of adipocytes, is found at higher levels in adipocytes and absent in preadipocytes. If exposed to tumor necrosis factor $\alpha$ (TNF $\alpha$ ), both preadipocytes and adipocytes show an increase of TNF $\alpha$ mRNA expression, leading to an augmented ability to activate endothelial cells and recruit monocytes. The same autocrine regulation was demonstrated in humans (2).

In metabolic syndrome, monocytes/macrophages accumulate lipids and infiltrate adipose tissue; in turn, adipocytes become fatter, larger and express novel molecules acquiring a 'macrophage-related gene profile' $(3,4)$. In such a vicious cycle, the distinction between adipocytes and macrophages becomes subtle. Indeed, there is a close relationship between immune and adipose cells, as reported in a study using a transcriptome profiling approach aimed at comparing macrophages and adipocytes (5). Macrophages and adipocytes both develop from mesoderm, but separate relatively early in embryogenesis, along with hematopoietic and mesenchymal lineages. Nevertheless, adipocyte and monocyte/macrophages are known to share many functional and antigenic features. In particular, if exposed to mediators of inflammation, the ability of adipocytes to secrete inflammatory cytokines, such as TNF $\alpha$ and IL-6, is enhanced $(6,7)$. Using profiling analysis, it was unequivocally demonstrated that adipose precursors can transdifferentiate into macrophages, in agreement with numerous studies on cellular plasticity in which the direct contact with differentiated cells induces the precursors to achieve the same specialized phenotype. Therefore, in fat tissue from obese patients, a fraction of infiltrated macrophages develops from transdifferentiation of stromal preadipocytes. High levels of proinflammatory cytokines in adipose tissue are positively related to insulin resistance, development of type 2 diabetes and obesity (8-11). Overall, the activation of adipose cells by the macrophage-derived mediators and the potent contribution of the other stromovascular fraction create a regulatory loop that strengthens the 
concept of a proinflammatory environment underlying metabolic disorders.

Pleiotropic effects of proinflammatory cytokines on adipose cells concern each stage of cell maturation. The impairment of the differentiation of the precursors and the inhibition of lipogenesis of new formed fat cells eventually leads to the formation of dysfunctional fat cells and to the worsening of the metabolic status (12).

The concept that sex steroids can modulate the immune system is in agreement with a higher incidence of autoimmune disorders in women compared to men $(13,14)$. Sex hormones have effects on cells of both the innate and adaptive response. An estrogen hormonal environment stimulates Th lymphocytes to secrete type 2 cytokines (IL-4, IL-5, IL-6, IL-10 and IL-13) that promote the synthesis of antibodies $(15,16)$. By contrast, androgens stimulate Th cells to produce type 1 cytokines (IFN $\gamma$, IL-2, TNF $\alpha$ ) which reduce Th2 activity and stimulate cell-mediated immunity (17).

In macrophages, a differentiated effect of sex hormones can be observed. Estrogens stimulate the production of IL1, IL-4, IL-6 and IL-10. By contrast, testosterone selectively increases the production of IL-1 $\beta$ and of IL-12 in monocytes (18). Moreover, testosterone does not show any effect on the production of $\mathrm{TNF} \alpha$ (18), whereas with regard to estrogens, there are contradictory results concerning their action on the production of this cytokine by monocytes $(19,20)$.

With the present study, we sought to investigate the effect of androgens on the ability of adipocytes to secrete proinflammatory and anti-inflammatory cytokines. Using a wellestablished cellular model (3T3-L1), we studied the trend of IL-1 $\beta$, IL-2, IL-6, IL-10, IL-12, IFN $\gamma$ and TNF $\alpha$ production during preadipocyte-to-adipocyte conversion obtained with different differentiation methods (21); we then investigated how dihydrotestosterone (DHT) can affect such a differentiation-dependent pattern of cytokine release from the nonimmune component of the adipose tissue.

\section{Materials and methods}

\section{Cell culture conditions and treatment}

Mouse 3T3-L1 fibroblasts were purchased from American Type Culture Collection (ATCC, Manassas, VA, USA) and were grown in $10 \% \mathrm{CO}_{2}$ in air at $37^{\circ} \mathrm{C}$ to confluence in Dulbecco's modified Eagle's medium (DMEM, Sigma-Aldrich, St. Louis, MO, USA) containing $10 \%$ newborn calf serum (NCS, Sigma-Aldrich), $100 \mathrm{units} / \mathrm{mL}$ penicillin and $100 \mu \mathrm{g} / \mathrm{mL}$ streptomycin (P/S, SigmaAldrich). Two days after confluence, the conversion of fibroblasts into mature adipocytes was induced by adding cells with DMEM containing $10 \%$ NCS, P/S and a differentiation cocktail (Cocktail 1: $1 \mu \mathrm{M}$ dexamethasone, $0.5 \mathrm{mM}$ IBMX and $10 \mu \mathrm{g} / \mathrm{mL}$ insulin; Cocktail 2: $125 \mu \mathrm{M}$ indomethacin, $5 \mu \mathrm{g} / \mathrm{mL}$ insulin) (day 0). Differentiation medium was removed after $48 \mathrm{~h}$ and replaced by DMEM containing $10 \% \mathrm{NCS}, \mathrm{P} / \mathrm{S}$ and $5 \mu \mathrm{g} / \mathrm{mL}$ insulin. Since day 0 and each 2 days, culture medium was changed and DHT supplementation was renewed in treated samples. Cell supernatants for cytokine assays were collected before the administration of the cocktail (day 0), at day 4, day 6 or at complete differentiation (day 8 ), after $60 \mathrm{~h}$ of serum starvation (medium supplemented with BSA
$2 \%$ and insulin \pm DHT). Cell supernatants were withdrawn, centrifuged to eliminate debris and frozen at $-80^{\circ} \mathrm{C}$ for further analyses.

\section{Quantification of lipid accumulation}

Oil Red O staining followed by spectrophotometric analysis was performed to measure lipid accumulation as previously described (22). Cells from three different wells were washed with phosphate buffered saline (Sigma-Aldrich) and fixed with 3.7\% (v/v) formaldehyde (Sigma-Aldrich) for $1 \mathrm{~h}$. A filtered $0.6 \%(\mathrm{w} / \mathrm{v})$ Oil Red O dye (Sigma-Aldrich) in 60\% (v/v) isopropanol was used. Wells were washed three times with distilled water and excess water was evaporated at $60^{\circ} \mathrm{C}$ for $1 \mathrm{~h}$. Oil Red $\mathrm{O}$ dye retained by lipid droplets was extracted by adding $100 \%$ isopropanol. The optical density of this solution was measured at a wavelength of $490 \mathrm{~nm}$ and results were expressed as percentage of Oil Red $\mathrm{O}$ absorbance of untreated cells control at the selected day \pm SD.

\section{SearchLight multiplex ELISA}

The measurement of proteins in cell supernatants (IL-1 $\beta$, IL-2, IL6, IL-10, IL-12, IFN $\gamma$ and $\mathrm{TNF} \alpha$ ) was performed using the SearchLight Protein Array Technology (Pierce Biotechnology, Rockford, IL, USA). This method consists of a multiplexed sandwich ELISA system and is used for the simultaneous quantitative measurement of analytes for which respective capture-antibodies are spotted in arrays within each well of a 96-well microplate. The multiplex ELISA assay was performed according to the manufacturer's instructions; $50 \mu \mathrm{L}$ of calibration standards or samples were analyzed twice and the mean value of measurements was used. The final chemiluminescent signal was detected with a cooled CCD camera (Aushon BioSystems, Billerica, MA, USA). The concentration of each analyte in the array was quantified by comparing the spot intensities for each unknown sample to the corresponding standard curves calculated from the standard sample results by the SearchLight Array Analyst Software. Integrated density values were proportional to the concentrations of bound proteins. Individual analytes were identified by the position of each specific capture antibody within the well. Standard curves, raw data and final $\mathrm{pg} / \mathrm{mL}$ concentrations for each analyte and each sample were reviewed in the array software and exported to Microsoft Excel Software (Microsoft Corp., USA). Results are expressed as means of three replicates of three independent experiments. Replicates were analyzed in duplicate on the 96-well microplate. Statistical comparisons between two groups were analyzed by Student's t-test and between several groups by one-way analysis of variance followed by Student's t-test. Probability values of $\mathrm{p}<0.05$ were considered statistically significant.

\section{Results}

\section{Effects of sex steroids on morphology and triglyceride accumulation during preadipocyte- to-adipocyte conversion}

Preadipocytes showed a fibroblast-like appearance and contained no lipid droplets. After induction of differentiation, they started to lose the elongated morphology, became spherical and gradually accumulated small lipid droplets. Within 20 days adipocytes appear filled with large lipid vesicles. The addition to the differentiation cocktail of DHT $10 \mathrm{nM}$ or $1 \mu \mathrm{M}$ since day 0 , in the presence of insulin and high- 
glucose maintained throughout adipocyte maturation, did not change the kinetic of differentiation, with the cells becoming round-shaped and accumulating lipid droplets in a similar extent to controls. If differentiation was induced by adding Cocktail 2, we observed a slower acquisition of the differentiated phenotype in both control and hormone-treated cells. Nevertheless, no difference could be observed in lipid staining or cell morphology after day 10 of differentiation.

As expected, control and treated adipocytes cultures showed a similar Oil Red O signal, measured at days 6, 10 and 14 , reflecting the observed trend of lipid accumulation. This was verified using both differentiation cocktails (Figure 1).

\section{Effect of androgens on cytokine production during adipogenesis}

IL-1 $\beta$, IL-2, IL-6, IL-10, IL-12 levels gradually increased during the conversion of preadipocytes into mature adipocytes (Figure 2). Basal levels of such cytokines at any stage of the differentiation process are below $15 \mathrm{pg} / \mathrm{mL}$, except for IL-6 for which levels ranged between 100 and 2000 pg/mL. By contrast, IFN $\gamma$ and TNF $\alpha$ secretion decreases with the acquisition of the differentiated phenotype (Figure 2).

IL-2 and IL-10 (Figure 2A) Cells exposed to DHT (10 nM) show a marked increase of IL-2 levels at later stages of differentiation (day 8: $10.7 \pm 0.5 \mathrm{pg} / \mathrm{mL}$ vs. $3.9 \pm 0.6 \mathrm{pg} / \mathrm{mL}$ of control, $\mathrm{p}<0.001)$, whereas at the higher dose $(1 \mu \mathrm{M}$ DHT $)$ they show a sharper increase at earlier stages (day 4: 13.2 \pm $0.8 \mathrm{pg} / \mathrm{mL}$ vs. $3.2 \pm 1 \mathrm{pg} / \mathrm{mL}$ of control, $\mathrm{p}<0.001$ ), without further increase.

IL-10 concentration in control cells rapidly reaches a plateau since day 4 of differentiation. Exposure to $10 \mathrm{nM}$ DHT induces an exponential increase of IL-10 production (day 8: $10.8 \pm 1.9 \mathrm{pg} / \mathrm{mL}$ vs. $4.1 \pm 1.3 \mathrm{pg} / \mathrm{mL}$ of control, $\mathrm{p}<0.001)$.

IL-1 $\beta$ and TNF $\boldsymbol{\alpha}$ (Figure 2B) Treatment with androgens blocks the positive trend of IL-1 $\beta$ production. Indeed, exposure to $10 \mathrm{nM}$ DHT induces a rapid plateau of cytokine production up to day 8 . If exposed to $1 \mu \mathrm{M}$ DHT, cells do not show any differentiation-dependent increase of IL-1 $\beta$. Levels of the cytokine remain constant since day $4(\mathrm{p}<0.05)$ and are 3 -fold lower than in control cells at day 8 of differentiation $(4.1 \pm 1.5 \mathrm{pg} / \mathrm{mL}$ vs. $11.9 \pm 0.6 \mathrm{pg} / \mathrm{mL}$ of control, $\mathrm{p}<0.01)$.

$\mathrm{TNF} \alpha$ production shows a decreasing trend during differentiation. Cells treated with both $10 \mathrm{nM}$ and $1 \mu \mathrm{M}$ DHT produce less $\mathrm{TNF} \alpha$ than control counterparts since day 4 of differentiation (10 $\mathrm{nM}$ and $1 \mu \mathrm{M}$ DHT, $\mathrm{p}<0.01)$. Moreover, with $1 \mu \mathrm{M}$ DHT, TNF $\alpha$ levels do not reach those of controls after the full maturation (day 8: $8.7 \pm 1.3 \mathrm{pg} / \mathrm{mL}$ vs. $16.4 \pm$ $1.3 \mathrm{pg} / \mathrm{mL}$ of control, $\mathrm{p}<0.01)$.

IFN $\gamma$, IL-6 and IL-12 (Figure 2B) IFN $\gamma$ production is significantly decreased in the presence of $1 \mu \mathrm{M}$ DHT at earlier stages of differentiation (day $4, \mathrm{p}<0.05$ ), reaching levels similar to control samples at day 8 of differentiation $(788.9 \pm 123 \mathrm{pg} / \mathrm{mL}$ vs. $734.9 \pm 76.3 \mathrm{pg} / \mathrm{mL}$ of control, not significant).
The differentiation-dependent increase of IL-6 is reduced after exposure to androgens. Indeed, at day 8 IL-6 levels are lowered by $\sim 1.8$-fold with $1 \mu \mathrm{M}$ DHT $(1067.8 \pm 357$ $\mathrm{pg} / \mathrm{mL}$ vs. $1891.1 \pm 341.4 \mathrm{pg} / \mathrm{mL}$ of control, $\mathrm{p}<0.001)$.

IL-12 concentration in DHT-treated cells rapidly reaches a plateau at day 4 of differentiation $(p<0.05)$, as opposite to the exponential increase of cytokine levels in control cells.

\section{Conclusions}

Our study gained new insights into the role of androgens during adipogenesis. Here, we describe for the first time how differentiating preadipocytes respond to androgen supplementation in terms of cytokine production. In adipose tissue, both immune and adipose cells contribute to the cytokine microenvironment. In the onset of insulin resistance, macrophages and adipocytes influence the biological functions of each other through the paracrine action of secreted mediators. Macrophage-derived cytokines can affect the maturation of the adipocyte precursor and impair the acquisition of a specialized phenotype (23). The incomplete differentiation of preadipocytes leads to the formation of smaller cells with an altered lipid metabolism that are less responsive to insulin signaling and produce more proinflammatory cytokines such as TNF $\alpha$ (24). Therefore, the impairment of differentiation can be seen as both a cause and a consequence of an altered cytokine profile within the adipose tissue, leading to the initiation of a chronic inflammation status that sustain obesity and diabetes.

In the present study, we demonstrate that androgens have significant effects on the pool of cytokines secreted by newly formed adipocytes. Indeed, the administration of DHT to differentiating 3T3-L1 preadipocytes significantly decreases the release of proinflammatory cytokines (IL-1 $\beta$, IL-6, TNF $\alpha$, IFN $\gamma$ and IL-12), whereas anti-inflammatory cytokines (IL2 and IL-10) are increased during the adipogenic process.

IL-2, a cytokine critical for $\mathrm{T}$ cell growth and development, has been shown to induce adiponectin secretion in human adipocytes, an adipokine with insulin-sensitizing and anti-inflammatory properties (25). IL-10 is a strong antiinflammatory cytokine that is able to inhibit TNF $\alpha$, IL-1 $\beta$ and IFN $\gamma$ secretion from macrophages (26) and do not affect adipocyte formation or adiponectin secretion (23). Here, we demonstrate that, if preadipocytes are differentiated in the presence of DHT, the differentiation-dependent increase of IL-2 and IL-10 release is further stimulated.

By contrast, DHT is able to completely revert the trend of release of IL-1 $\beta$ and TNF $\alpha$. Indeed, in both cases with $1 \mu \mathrm{M}$ DHT, the production of such cytokines is effectively suppressed since the very early stages of differentiation. A less marked effect is observed for IFN $\gamma$, for which levels are significantly lowered at day 4 only with the higher DHT concentration, but eventually equal those of control cells at the end of the adipogenic conversion (day 8). The same trend is observed on $\mathrm{TNF} \alpha$ if cells are administered with $10 \mathrm{nM}$ DHT. IL-6 and IL-12 release is significantly reduced only with $1 \mu \mathrm{M}$ DHT at day 8 of differentiation. 

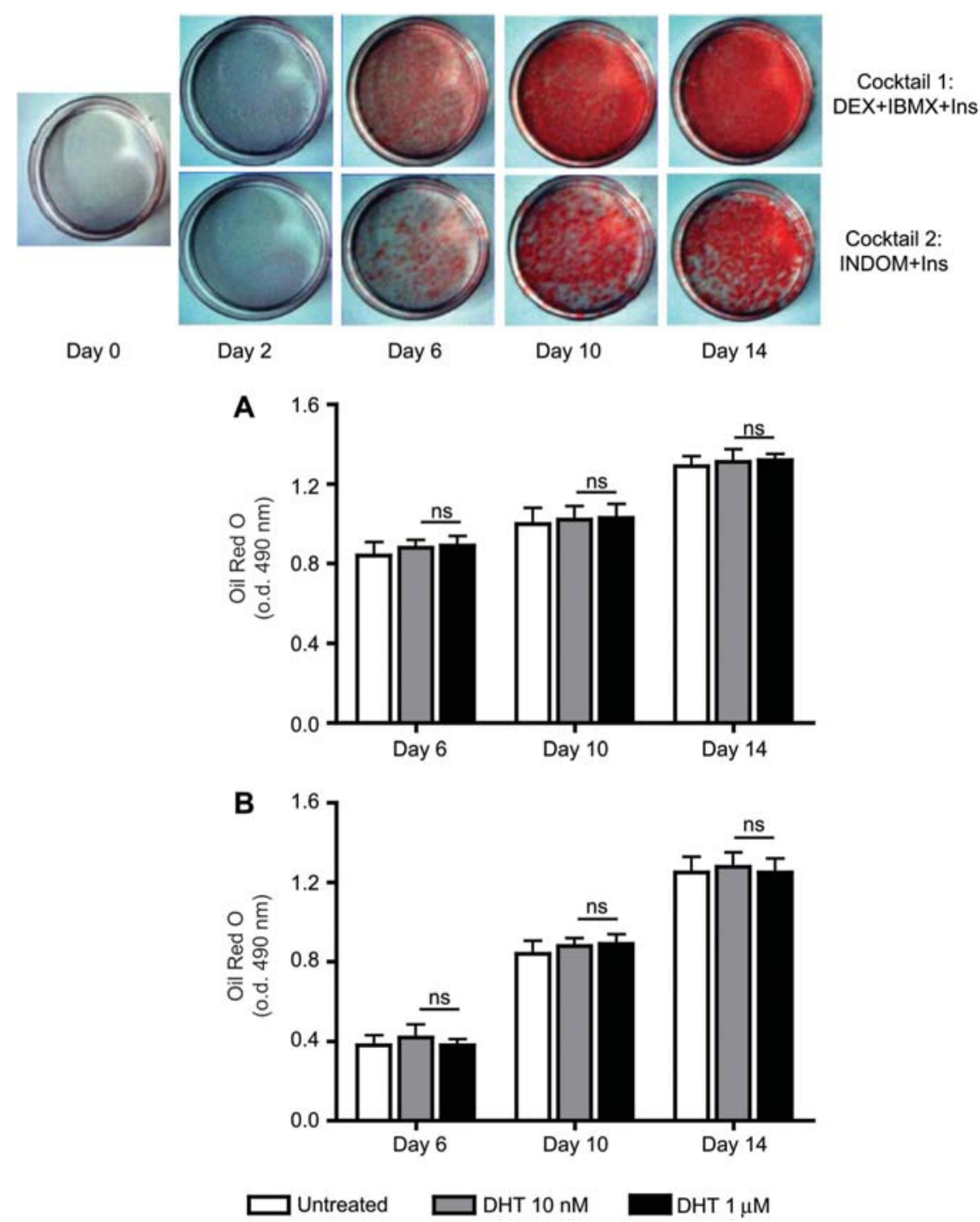

Figure 1 Quantification of adipocyte development by measuring lipid accumulation (Oil Red O staining) at days 6, 10 and 14 of differentiation after treatment with dihydrotestosterone.

Oil Red O staining of intracellular triglycerides was performed at days 6, 10 and 14 of differentiation. (Upper panel) Representative culture dishes at days $0,2,6,10$ and 14 of differentiation with either Cocktail 1 or Cocktail 2. (A) Cells differentiated with Cocktail 1: dexamethasone + IBMX + insulin. (B) Cells differentiated with Cocktail 2: indomethacin + insulin (see Methods). White bars represent untreated cells, gray bars represent cells receiving $10 \mathrm{nM}$ DHT and black bars represent cells receiving $1 \mu \mathrm{M}$ DHT since day 0 of differentiation. Results are means \pm SD $(n=3)$. Difference compared to untreated cultures is not significant $(p>0.05)$ at any DHT dose at any time (ns).

It has been demonstrated that IL- $1 \beta$, IFN $\gamma$ and $\mathrm{TNF} \alpha$ inhibit the differentiation of adipose precursors, promote the maintenance of a fibroblast-like phenotype, support a proliferative state with conserved Wnt signaling and induce the secretion of inflammatory markers such as IL-6, MCP-1 and PAI-1 (23). Moreover, TNF $\alpha$ is able to induce a dedifferentiation of mature adipocytes and inhibits the expression of several genes of normal metabolism and insulin sensitivity such as glycerol-3-phosphate dehydrogenase, lipoprotein lipase, acetyl-CoA carboxylase, fatty acid synthase (27), IRS1 and GLUT4 (28). IL-6 shows a similar, although less potent, anti-adipogenic effect. Consistently with their antidifferentiative effect, exposure of subcutaneous human preadipocytes to IL-1 $\beta$, IFN $\gamma$ and TNF $\alpha$ completely blocked adiponectin secretion (23). TNF $\alpha$ stimulation is also able to induce a sharp increase of IL-12 in 3T3-L1, suggesting that IL-12 is strongly related to the inflammatory status (29).

The finding that androgens can act as a prodifferentiative force arises from the dual effect of DHT observed in developing adipocytes. On one hand, androgen added to the differentiation medium causes a fast drop of proinflammatory antidifferentiative cytokines (TNF $\alpha, \mathrm{IL}-1 \beta$ and IFN $\gamma$ ), and on the other hand, this occurs without changes in the rate and magnitude of lipid accumulation. The androgen-induced reduction of TNF $\alpha$, IL-1 $\beta$ and IFN $\gamma$ from the microenvironment that is nourishing the differentiating cell has positive 

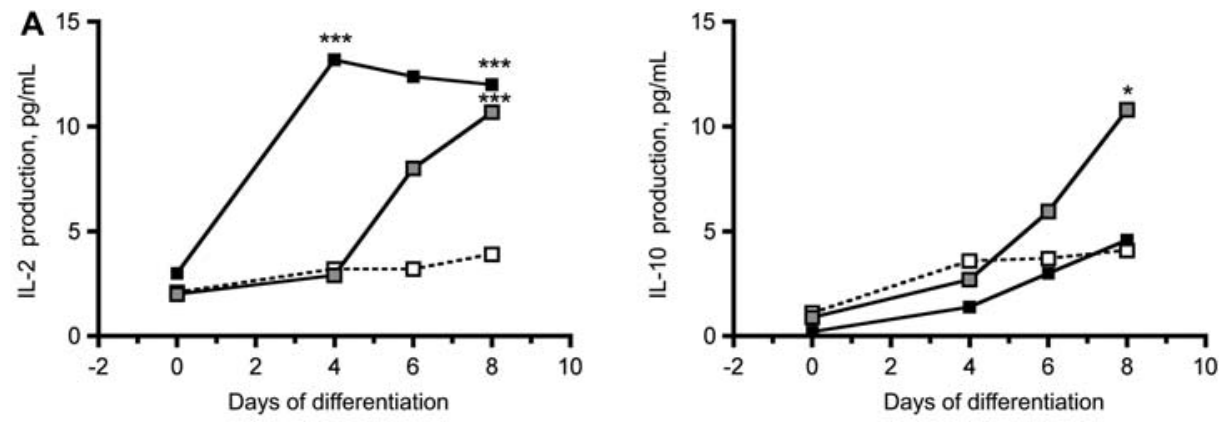

- - - Contro

$\rightarrow \square-$ DHT $10 \mathrm{nM}$

$\rightarrow-\mathrm{DHT} 1 \mu \mathrm{M}$
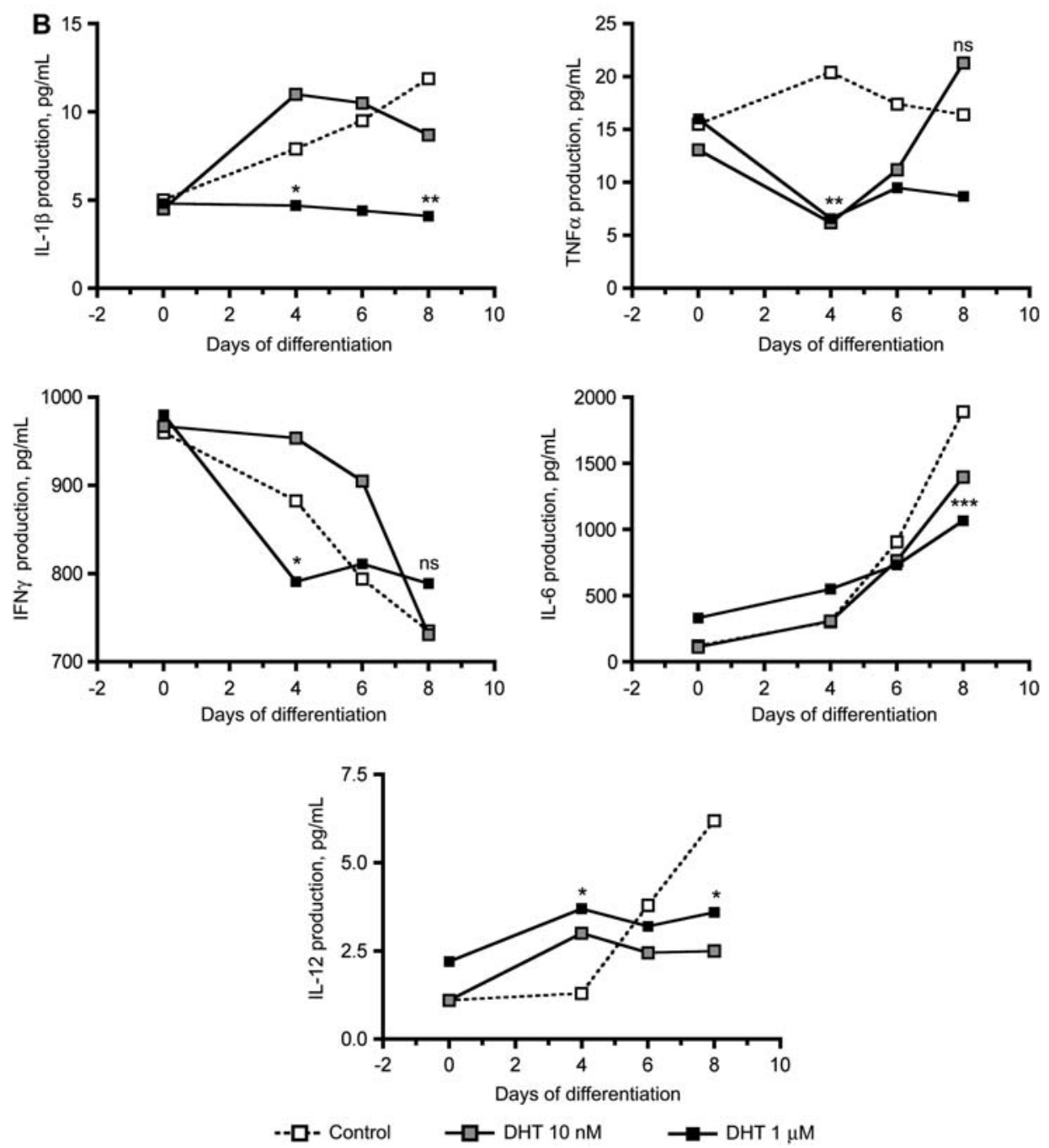

Figure 2 Differentiation-dependent secretion of cytokines after treatment with DHT. Levels of each cytokine were measured by the SearchLight multiplex ELISA at days 0, 4, 6 and 8 of differentiation and results are expressed in pg/mL. White squares are the untreated cells, gray squares are cells receiving $10 \mathrm{nM}$ DHT and black squares are cells receiving $1 \mu \mathrm{M}$ DHT since day 0 of differentiation. (A) Anti-inflammatory cytokine secretion. (B) Proinflammatory cytokine secretion. Three independent experiments were performed. $* \mathrm{p}<0.05$, $* * \mathrm{p}<0.01, * * * \mathrm{p}<0.001$ indicate significant difference compared to the untreated culture at the corresponding day of differentiation.

repercussions on insulin-sensitivity, glucose internalization and the acquisition of a mature phenotype. Confirmation of the beneficial effects is strengthened by the decrease of IL6 and IL-12, and the increase of IL-2 and IL-10 observed at the final stage of adipogenesis. Moreover, we found that in the presence of prodifferentiative conditioning, DHT does not alter the rate of lipid accumulation, as measured by Oil Red O triglyceride staining. Overall, exposure to androgens during the activation and the progress of the adipogenic conversion induces a dissociation of fat accumulation and cyto- 
kine secretion that contributes to the successful maturation into adipose cells with a better metabolic profile.

In conclusion, we have provided evidence that androgens have significant effects on the ability of differentiating preadipocytes to release proinflammatory (IL-1 $\beta, \mathrm{TNF} \alpha$, IFN $\gamma$, IL-6 and IL-12) and anti-inflammatory cytokines (IL-2 and IL-10). Androgens are shown to promote the formation of an anti-inflammatory milieu that favors adipose cell maturation, independently of intracellular fat accumulation. The crosstalk between androgens and immunomodulatory mediators might play a role in ameliorating the chronic inflammatory status and, in turn, the adipose cell dysfunction that are common features of the metabolic syndrome.

\section{References}

1. Mack I, BelAiba RS, Djordjevic T, Gorlach A, Hauner H, Bader BL. Functional analyses reveal the greater potency of preadipocytes compared with adipocytes as endothelial cell activator under normoxia, hypoxia, and TNFalpha exposure. Am J Physiol Endocrinol Metab 2009;297:E735-48.

2. Zhang HH, Kumar S, Barnett AH, Eggo MC. Dexamethasone inhibits tumor necrosis factor-alpha-induced apoptosis and interleukin- 1 beta release in human subcutaneous adipocytes and preadipocytes. J Clin Endocrinol Metab 2001;86:2817-25.

3. Weisberg SP, McCann D, Desai M, Rosenbaum M, Leibel RL, Ferrante AW Jr. Obesity is associated with macrophage accumulation in adipose tissue. J Clin Invest 2003;112:1796-808.

4. Xu H, Barnes GT, Yang Q, Tan G, Yang D, Chou CJ, Sole J, Nichols A, Ross JS, Tartaglia LA, Chen H. Chronic inflammation in fat plays a crucial role in the development of obesityrelated insulin resistance. J Clin Invest 2003;112:1821-30.

5. Charriere G, Cousin B, Arnaud E, André M, Bacou F, Penicaud L, Casteilla L. Preadipocyte conversion to macrophage. Evidence of plasticity. J Biol Chem 2003;278:9850-5.

6. Lin Y, Lee H, Berg AH, Lisanti MP, Shapiro L, Scherer PE. The lipopolysaccharide-activated toll-like receptor (TLR)-4 induces synthesis of the closely related receptor TLR-2 in adipocytes. J Biol Chem 2000;275:24255-63.

7. Rajala MW, Scherer PE. Minireview: the adipocyte - at the crossroads of energy homeostasis, inflammation, and atherosclerosis. Endocrinology 2003;144:3765-73.

8. Hotamisligil GS, Arner P, Caro JF, Atkinson RL, Spiegelman BM. Increased adipose tissue expression of tumor necrosis factor-alpha in human obesity and insulin resistance. J Clin Invest 1995;95:2409-15.

9. Mohamed-Ali V, Goodrick S, Rawesh A, Katz DR, Miles JM, Yudkin JS, Klein S, Coppack SW. Subcutaneous adipose tissue releases interleukin-6, but not tumor necrosis factor-alpha, in vivo. J Clin Endocrinol Metab 1997;82:4196-200.

10. Isidori AM, Caprio M, Strollo F, Moretti C, Frajese G, Isidori A, Fabbri A. Leptin and androgens in male obesity: evidence for leptin contribution to reduced androgen levels. J Clin Endocrinol Metab 1999;84:3673-80.

11. Isidori AM, Strollo F, More M, Caprio M, Aversa A, Moretti C, Frajese G, Riondino G, Fabbri A. Leptin and aging: correlation with endocrine changes in male and female healthy adult populations of different body weights. J Clin Endocrinol Metab 2000;85:1954-62.

12. Isidori AM, Lenzi A. Risk factors for androgen decline in older males: lifestyle, chronic diseases and drugs. J Endocrinol Invest 2005;28(Suppl 3):14-22.
13. Jacobson DL, Gange SJ, Rose NR, Graham NM. Epidemiology and estimated population burden of selected autoimmune diseases in the United States. Clin Immunol Immunopathol 1997; 84:223-43.

14. Isidori AM, Giannetta E, Pozza C, Bonifacio V, Isidori A. Androgens, cardiovascular disease and osteoporosis. J Endocrinol Invest 2005;28(Suppl 10):73-9.

15. Beagley KW, Gockel CM. Regulation of innate and adaptive immunity by the female sex hormones oestradiol and progesterone. FEMS Immunol Med Microbiol 2003;38:13-22.

16. Tanriverdi F, Silveira LF, MacColl GS, Bouloux PM. The hypothalamic-pituitary-gonadal axis: immune function and autoimmunity. J Endocrinol 2003;176:293-304.

17. Grimaldi CM, Cleary J, Dagtas AS, Moussai D, Diamond B. Estrogen alters thresholds for B cell apoptosis and activation. J Clin Invest 2002;109:1625-33.

18. Posma E, Moes H, Heineman MJ, Faas MM. The effect of testosterone on cytokine production in the specific and non-specific immune response. Am J Reprod Immunol 2004;52:237-43.

19. Asai K, Hiki N, Mimura Y, Ogawa T, Unou K, Kaminishi M. Gender differences in cytokine secretion by human peripheral blood mononuclear cells: role of estrogen in modulating LPSinduced cytokine secretion in an ex vivo septic model. Shock 2001;16:340-3.

20. Rogers A, Eastell R. The effect of 17beta-estradiol on production of cytokines in cultures of peripheral blood. Bone 2001;29:30-4.

21. Norman D, Isidori AM, Frajese V, Caprio M, Chew SL, Grossman AB, Clark AJ, Michael Besser G, Fabbri A. ACTH and alpha-MSH inhibit leptin expression and secretion in 3T3-L1 adipocytes: model for a central-peripheral melanocortin-leptin pathway. Mol Cell Endocrinol 2003;200:99-109.

22. Ramirez-Zacarias JL, Castro-Munozledo F, Kuri-Harcuch W. Quantitation of adipose conversion and triglycerides by staining intracytoplasmic lipids with Oil red O. Histochemistry 1992;97: 493-7.

23. Simons PJ, van den Pangaart PS, van Roomen CP, Aerts JM, Boon L. Cytokine-mediated modulation of leptin and adiponectin secretion during in vitro adipogenesis: evidence that tumor necrosis factor-alpha- and interleukin-1beta-treated human preadipocytes are potent leptin producers. Cytokine 2005; 32:94-103.

24. Kirkland JL, Dobson DE. Preadipocyte function and aging: links between age-related changes in cell dynamics and altered fat tissue function. J Am Geriatr Soc 1997;45:959-67.

25. Sankale JL, Tong Q, Hadigan CM, Tan G, Grinspoon SK, Kanki PJ, Hotamisligil GS. Regulation of adiponectin in adipocytes upon exposure to HIV-1. HIV Med 2006;7:268-74.

26. Opal SM, DePalo VA. Anti-inflammatory cytokines. Chest 2000;117:1162-72.

27. Petruschke T, Hauner H. Tumor necrosis factor-alpha prevents the differentiation of human adipocyte precursor cells and causes delipidation of newly developed fat cells. J Clin Endocrinol Metab 1993;76:742-7.

28. Gustafson B, Smith U. Cytokines promote Wnt signaling and inflammation and impair the normal differentiation and lipid accumulation in 3T3-L1 preadipocytes. J Biol Chem 2006; 281:9507-16.

29. Cho ML, Kang JW, Moon YM, Nam HJ, Jhun JY, Heo SB, Jin HT, Min SY, Ju JH, Park KS, Cho YG, Yoon CH, Park SH, Sung YC, Kim HY. STAT3 and NF-kappaB signal pathway is required for IL-23-mediated IL-17 production in spontaneous arthritis animal model IL-1 receptor antagonist-deficient mice. J Immunol 2006;176:5652-61. 